\title{
Effect of therapeutic plasma concentrations of non-steroidal anti-inflammatory drugs on the production of reactive oxygen species by activated rat neutrophils
}

I.M.M. Paino, V.F. Ximenes, L.M. da Fonseca,

M.P.P. Kanegae, N.M. Khalil and I.L. Brunetti
Departamento de Análises Clínicas, Faculdade de Ciências Farmacêuticas, Universidade Estadual Paulista (UNESP), Araraquara, SP, Brasil
Correspondence

I.L. Brunetti

Faculdade de Ciências Farmacêuticas UNESP

14801-902 Araraquara, SP

Brasil

Fax: +55-16-222-0073

E-mail: brunetti@fcfar.unesp.br

Research supported by Laboratório de Análises Clínicas, Faculdade de Ciências Farmacêuticas (NAC-FCF), UNESP, and CAPES.

Publication supported by FAPESP.

Received April 22, 2004

Accepted January 14, 2005

\begin{abstract}
The release of reactive oxygen specie (ROS) by activated neutrophil is involved in both the antimicrobial and deleterious effects in chronic inflammation. The objective of the present investigation was to determine the effect of therapeutic plasma concentrations of non-steroidal anti-inflammatory drugs (NSAIDs) on the production of ROS by stimulated rat neutrophils. Diclofenac $(3.6 \mu \mathrm{M})$, indomethacin $(12 \mu \mathrm{M})$, naproxen $(160 \mu \mathrm{M})$, piroxicam $(13 \mu \mathrm{M})$, and tenoxicam $(30 \mu \mathrm{M})$ were incubated at $37^{\circ} \mathrm{C}$ in PBS $(10 \mathrm{mM}), \mathrm{pH} 7.4$, for 30 min with rat neutrophils $\left(1 \times 10^{6}\right.$ cells $\left./ \mathrm{ml}\right)$ stimulated by phorbol-12-myristate-13-acetate $(100 \mathrm{nM})$. The ROS production was measured by luminol and lucigenin-dependent chemiluminescence. Except for naproxen, NSAIDs reduced ROS production: $58 \pm$ $2 \%$ diclofenac, $90 \pm 2 \%$ indomethacin, $33 \pm 3 \%$ piroxicam, and $45 \pm$ $6 \%$ tenoxicam $(\mathrm{N}=6)$. For the lucigenin assay, naproxen, piroxicam and tenoxicam were ineffective. For indomethacin the inhibition was $52 \pm 5 \%$ and diclofenac showed amplification in the light emission of $181 \pm 60 \%(\mathrm{~N}=6)$. Using the myeloperoxidase (MPO)/ $\mathrm{H}_{2} \mathrm{O}_{2}$ /luminol system, the effects of NSAIDs on MPO activity were also screened. We found that NSAIDs inhibited both the peroxidation and chlorinating activity of MPO as follows: diclofenac (36 \pm $10,45 \pm 3 \%)$, indomethacin $(97 \pm 2,100 \pm 1 \%)$, naproxen $(56 \pm 8,76$ $\pm 3 \%$ ), piroxicam $(77 \pm 5,99 \pm 1 \%)$, and tenoxicam $(90 \pm 2,100 \pm 1 \%)$, respectively $(\mathrm{N}=3)$. These results show that therapeutic levels of NSAIDs are able to suppress the oxygen-dependent antimicrobial or oxidative functions of neutrophils by inhibiting the generation of hypochlorous acid.
\end{abstract}

Key words

- Non-steroidal

anti-inflammatory drugs

- Neutrophils

- Myeloperoxidase

- Hypochlorous acid

- Reactive oxygen species

- Chemiluminescence 


\section{Introduction}

The innate immune response comprises a series of events which prepare the organism to act against intruding agents. The liberation of vasoactive substances and acute phase protein and the migration of neutrophil polymorphonuclear leukocytes (PMN) to the inflammatory site are among the first events when pathogens, chemical agents and physical factors challenge the body. Indeed, neutrophils, which represent 50 to $70 \%$ of the total circulating leukocytes, constitute the first line of defense against infectious agents or non-self substances that penetrate the body's physical barrier (1). Upon activation, non-mitochondrial oxygen uptake is initiated by the PMN, resulting in the production of reactive oxygen species (ROS). This process, known as oxidative burst, is the result of the assembly of the multi-enzyme NADPH-oxidase system that promotes the one-electron reduction of oxygen to superoxide anion (2). Next, this species is reduced to hydrogen peroxide in a reaction catalyzed by superoxide dismutase and finally hydrogen peroxide is used by the enzyme myeloperoxidase (MPO) to oxidize chloride to hypochlorous acid $(\mathrm{HOCl})$ (3-5). This highly oxidant chemical has been proposed to be the main agent responsible for the antimicrobial action of PMN. However, it is also an important component regarding its action on the tissue damage that characterizes chronic inflammation. $\mathrm{HOCl}$ reacts with unsaturated fatty acids and cholesterol generating chlorohydrins, promotes the oxidation of proteins through the chlorination of tyrosine and tryptophan residues and mediates the production of protein carbonyls via the breakdown of chloramines to aldehydes (6-10). Moreover, there is accumulating evidence demonstrating that some intracellular signaling pathways are redox sensitive and ROS are involved in regulating the production of some biochemical mediators of inflammation $(11,12)$. In this respect, non-steroidal anti-inflammatory drugs (NSAIDs) have been studied in terms of their effect on ROS produc- tion since, in addition to having a widely accepted mechanism of action by inhibition of the enzymes involved in the production of proinflammatory lipid-derived mediators, these compounds may also interact with the oxidants produced by phagocytic cells (13-16).

In the present investigation, we studied the effect of therapeutic plasma concentrations of NSAIDs on ROS generation by stimulated rat neutrophils. Using the purified MPO model we found that the NSAIDs are both able to inhibit the formation of $\mathrm{HOCl}$ and to scavenge it. Additionally, diclofenac has a pro-oxidant activity by promoting the generation of superoxide anion.

\section{Material and Methods}

\section{Chemicals}

Phorbol-12-myristate-13-acetate (PMA), luminol, lucigenin, sodium borohydride, 5,5'dithio-bis(2-nitrobenzoic acid, DTNB), sodium hypochloride, and Ficoll-Hypaque 1077 were purchased from Sigma (St. Louis, MO, USA). Hydrogen peroxide (30\%) was purchased from Peróxidos do Brazil (São Paulo, SP, Brazil). MPO (E.C. 1.11.1.7) was purchased from Calbiochem (San Diego, CA, USA). Diclofenac and naproxen were purchased from Purifarma S.A. (São Paulo, SP, Brazil), piroxicam from Natural Farma S.A. (Belém, PA, Brazil), tenoxicam from S.P. Farma (São Paulo, SP, Brazil) and indomethacin from Sigma. All the reagents used for buffer preparation were of analytical grade.

\section{Isolation and purification of rat neutrophils}

A 5\% oyster glycogen solution (dissolved in $0.85 \% \mathrm{NaCl}$ ) was injected into the peritoneum of anesthetized rats. The animals were kept with food and liquid ad libitum and sacrificed $12 \mathrm{~h}$ later and $20 \mathrm{ml}$ calcium-free Dulbecco's phosphate-buffered saline (PBSD) (17) containing $10 \mathrm{IU}$ heparin per $\mathrm{ml}$ was injected into the peritoneal cavity. The exu- 
date was collected and centrifuged for $3 \mathrm{~min}$ at $200 \mathrm{~g}$. The cell pellet was layered on FicollHypaque 1077 and centrifuged for $25 \mathrm{~min}$ at $1000 \mathrm{~g}$. PMN cells were collected, washed and kept in ice-cold PBS-D until required.

\section{Cytotoxic effect of NSAIDs}

PMN $\left(1 \times 10^{6}\right.$ cells $\left./ \mathrm{ml}\right)$ were incubated at $37^{\circ} \mathrm{C}$ in PBS-D with or without the NSAIDs for $30 \mathrm{~min}$. Twenty-five microliters of the supernatant was used to measure the activity of lactate dehydrogenase (18).

\section{Chemiluminescence}

PMN $\left(1 \times 10^{6}\right.$ cells $\left./ \mathrm{ml}\right)$ were pre-incubated at $37^{\circ} \mathrm{C}$ in PBS-D with $10 \mu \mathrm{mol} / 1$ luminol or $10 \mu \mathrm{mol} / \mathrm{l}$ lucigenin and with therapeutic or 10 times higher concentrations of the NSAIDs (tests) or without the NSAIDs (controls) for $30 \mathrm{~min}$. The reaction was started by adding $100 \mathrm{nmol} / \mathrm{l}$ PMA and chemiluminescence was measured for 30 $\min (19)$.

Chemiluminescence assay using purified MPO

Chlorinating activity. MPO (50 mU/ml) was incubated at $37^{\circ} \mathrm{C}$ in PBS-D with 6 $\mu \mathrm{mol} / \mathrm{l}$ luminol and $67 \mu \mathrm{mol} / 1 \mathrm{H}_{2} \mathrm{O}_{2}$ plus the NSAIDs (tests) or without the NSAIDs (controls). The reaction was started by adding $\mathrm{H}_{2} \mathrm{O}_{2}$ and chemiluminescence measured for 5 min.

Peroxidation activity. The assay was carried out as described for chlorinating activity, but chloride was absent in the buffer $\left(\mathrm{PBS} / \mathrm{MgSO}_{4}\right)$. The reactions were carried out in a BIOOrbit model 1251 luminometer (Turku, Finland) (20).

\section{Oxygen uptake by neutrophils}

$\operatorname{PMN}\left(4 \times 10^{6}\right.$ cells $\left./ \mathrm{ml}\right)$ were incubated at $37^{\circ} \mathrm{C}$ in PBS-D with or without $36 \mu \mathrm{mol} / 1$ diclofenac. A Yellow Spring 5300 oxygen monitor (YSI, Cincinnati, OH, USA) was set at $100 \%$ and the reaction was started by adding $100 \mathrm{ng} / \mathrm{ml}$ PMA.

\section{Hypochlorous acid scavenging (5-thio-2-nitrobenzoic acid assay)}

Control. The absorbance of 5-thio-2nitrobenzoic acid (TNB) at $412 \mathrm{~nm}$ was measured before and after the addition of 15 $\mu \mathrm{mol} / 1 \mathrm{HOCl}$ to $48 \mu \mathrm{mol} / \mathrm{l} \mathrm{TNB}$ in PBS-D at $37^{\circ} \mathrm{C}$. The decrease in absorbance at $412 \mathrm{~nm}$ is correlated with the concentration of $\mathrm{HOCl}$.

Tests. The NSAIDs were incubated at $37^{\circ} \mathrm{C}$ in PBS-D containing $15 \mu \mathrm{mol} / \mathrm{l} \mathrm{HOCl}$ for $10 \mathrm{~min}$. Then $48 \mu \mathrm{mol} / \mathrm{l} \mathrm{TNB}$ was added and absorbance was measured. The scavenging of $\mathrm{HOCl}$ by NSAIDs is measured by the reduction of absorbance at $412 \mathrm{~nm}$ using the control as reference. TNB solutions were prepared daily by reduction of DTNB as described (21).

\section{Statistical analysis}

Data are reported as means $\pm \mathrm{SD}$ and the Student $t$-test was used to determine the difference between test and control preparations, with the level of significance set at $\mathrm{P}<$ 0.05 .

\section{Results}

The NSAID concentrations reported here are the mean plasma level detected after administration of these drugs at their therapeutic oral dosage in different inflammatory diseases (22-24).

The toxicity of the drugs was assessed since their inhibitory effects on ROS production may be linked to non-stimulated neutrophil dysfunction. The assays were performed by measuring the liberation of the enzyme lactate dehydrogenase when the cells were incubated with the drugs (18). The concentrations of NSAIDs tested here were not toxic to the cells (Table 1). 


\begin{tabular}{|c|c|}
\hline NSAID $(\mu \mathrm{M})$ & $\begin{array}{c}\text { Lactate dehydrogenase } \\
\text { activity (U/I) }\end{array}$ \\
\hline \multicolumn{2}{|l|}{ Diclofenac } \\
\hline $3.6^{a}$ & $17 \pm 3$ \\
\hline $36^{b}$ & $22 \pm 3$ \\
\hline \multicolumn{2}{|c|}{ Indomethacin } \\
\hline $12^{a}$ & $22 \pm 1$ \\
\hline $120^{b}$ & $27 \pm 5$ \\
\hline \multicolumn{2}{|l|}{ Naproxen } \\
\hline $160^{a}$ & $20 \pm 4$ \\
\hline $1600^{\mathrm{b}}$ & $25 \pm 5$ \\
\hline \multicolumn{2}{|l|}{ Piroxicam } \\
\hline $13^{a}$ & $28 \pm 2$ \\
\hline $130^{\mathrm{b}}$ & $32 \pm 5$ \\
\hline \multicolumn{2}{|l|}{ Tenoxicam } \\
\hline $30^{a}$ & $24 \pm 4$ \\
\hline $300^{b}$ & $26 \pm 3$ \\
\hline
\end{tabular}

Data are reported as the means \pm SD of 6 experiments. Lactate dehydrogenase activity was measured in the extracellular medium when neutrophils were incubated with NSAIDs. aTherapeutic plasma concentration; bten times higher than the therapeutic plasma concentration. The control in the absence of NSAIDs was $19 \pm 1 \mathrm{U} /$ and neutrophil disrupted by sonication was $95 \pm$ $6 \mathrm{U} / \mathrm{l}$. NSAIDs $=$ nonsteroidal anti-inflammatory drugs.

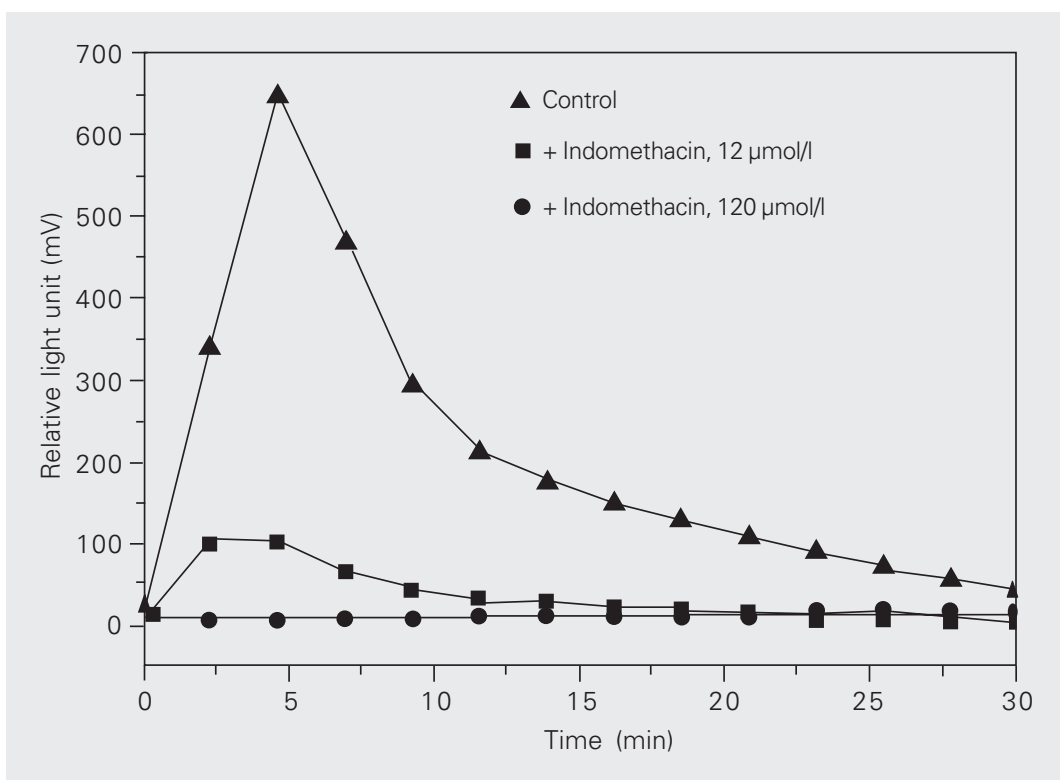

Figure 1. Typical light emission of luminol-dependent neutrophil chemiluminescence and inhibition by indomethacin. The neutrophils were stimulated with phorbol-12-myristate13-acetate. The traces are representative of 6 experiments.
Table 2. The effect of NSAIDs on luminol- and lucigenindependent neutrophil chemiluminescence.

\begin{tabular}{|c|c|c|}
\hline NSAID $(\mu \mathrm{M})$ & $\begin{array}{c}\text { Luminol } \\
\text { (\% inhibition) }\end{array}$ & $\begin{array}{c}\text { Lucigenin } \\
\text { (\% inhibition }\end{array}$ \\
\hline \multicolumn{3}{|l|}{ Diclofenac } \\
\hline $3.6^{a}$ & $58 \pm 2^{*}$ & Amplifiedc \\
\hline $36^{\mathrm{b}}$ & $65 \pm 10^{*}$ & Amplified $^{d}$ \\
\hline \multicolumn{3}{|l|}{ Indomethacin } \\
\hline $12^{\mathrm{a}}$ & $90 \pm 2 *$ & $52 \pm 5^{*}$ \\
\hline $120^{b}$ & $99 \pm 2^{*}$ & $72 \pm 6^{*}$ \\
\hline \multicolumn{3}{|l|}{ Naproxen } \\
\hline $160^{a}$ & NS & NS \\
\hline $1600^{b}$ & $42 \pm 7^{*}$ & NS \\
\hline \multicolumn{3}{|l|}{ Piroxicam } \\
\hline $13^{a}$ & $33 \pm 3^{*}$ & NS \\
\hline $130^{\mathrm{b}}$ & $48 \pm 2^{*}$ & NS \\
\hline \multicolumn{3}{|l|}{ Tenoxicam } \\
\hline $30^{a}$ & $45 \pm 6^{*}$ & NS \\
\hline $300^{b}$ & $61 \pm 2^{*}$ & NS \\
\hline
\end{tabular}

Data are reported as the means \pm SD of 6 experiments. ${ }^{a}$ Therapeutic plasma concentration; b ten times higher than the therapeutic plasma concentration; Camplification of $181 \pm 60 \%$; damplification of $280 \pm 90 \%$. NSAIDs $=$ nonsteroidal anti-inflammatory drugs.

${ }^{*} \mathrm{P}<0.05$ compared to controls: $3.0 \pm 0.7 \times 10^{5}$ $(\mathrm{mV} \cdot \mathrm{s})$ for luminol assay or $5.6 \pm 1.6 \times 10^{4}(\mathrm{mV} \cdot \mathrm{s})$ for lucigenin assay (Student $t$-test). NS $=$ nonsignificant.

The effects of the NSAIDs at their therapeutic or 10 times higher plasma concentrations on total ROS production were studied in luminol- or lucigenin-dependent chemiluminescence assays of rat neutrophils stimulated with PMA. The reactions were triggered by the stimulus and monitored for 30 min. The integrated light emission was taken as the analytical parameter. A typical lightemission profile and the suppressive effect of indomethacin at the therapeutic or 10 times higher plasma concentration are shown in Figure 1 for illustration.

Table 2 presents the inhibitory effects on luminol and lucigenin chemiluminescence observed when the NSAIDs were added to the reaction medium. In agreement with results reported for human neutrophils, NSAIDs at therapeutic concentrations are effective inhibitors of luminol chemilumines- 
cence $(19,25,26)$. Except for indomethacin and diclofenac, lucigenin chemiluminescence was not affected by NSAIDs. Moreover, diclofenac had the opposite effect, increasing lucigenin chemiluminescence. Since lucigenin is supposed to be a specific probe for superoxide anion (27-29), which is the primary reactive species formed during the oxidative burst, we also studied the effect of these drugs on oxygen consumption by activated neutrophils. In agreement with the chemiluminescence assay, diclofenac had a small but statistically significant $(\mathrm{P}<0.05)$ promoting effect on superoxide anion generation, since the oxygen uptake increased (Figure 2).

The luminol-dependent chemiluminescent assay lacks specificity regarding the ROS generated upon neutrophil activation (30); therefore, experiments were performed to determine the effect of the drugs on the activity of the MPO/ $\mathrm{H}_{2} \mathrm{O}_{2}$ enzymatic system. Two parameters were studied, i.e., peroxidation activity and chlorinating activity, in the absence and in the presence of chloride anion in the buffer, respectively. The reactions were monitored for $5 \mathrm{~min}$ and triggered by adding $\mathrm{H}_{2} \mathrm{O}_{2}$. The integrated light emission was taken as the analytical parameter. Both the peroxidation and chlorinating activities were strongly inhibited by the NSAIDs at the concentrations tested (Table 3).

The scavenging of pure $\mathrm{HOCl}$ by the NSAIDs was studied in the TNB assay. In this experiment, the suppression of TNB oxidation to DTNB is an indication of the capacity of NSAIDs to scavenge $\mathrm{HOCl}$. For illustration, a typical absorption spectrum showing the oxidation of TNB to DTNB by $\mathrm{HOCl}$ and the effect of diclofenac is shown in Figure 3. The $\mathrm{HOCl}$ scavenging property of the NSAIDs studied here is shown in the Table 3. Piroxicam, tenoxicam and the higher dose of diclofenac were able to react with $\mathrm{HOCl}$. On the other hand, indomethacin and naproxen did not scavenge $\mathrm{HOCl}$ in a statistically significant manner (Table 3 ).

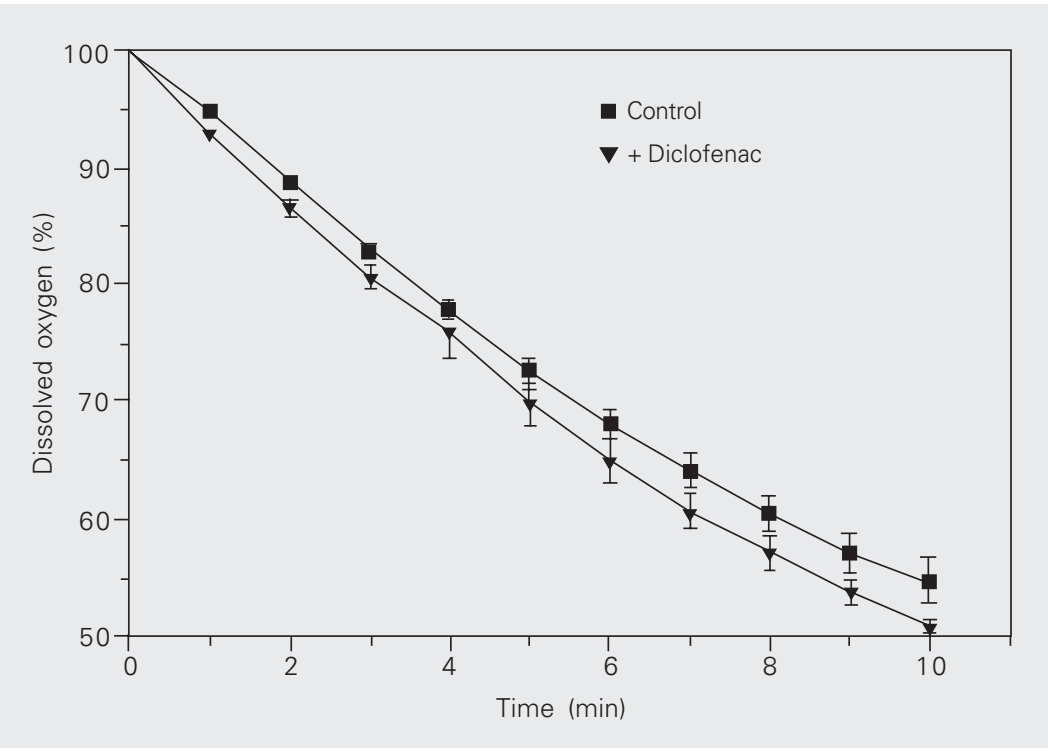

Figure 2. Effect of diclofenac on oxygen uptake by stimulated rat neutrophils. The traces are representative of 3 experiments.

Table 3. Inhibition of the peroxidation and chlorinating activities of myeloperoxidase by NSAIDs and reactivity with hypochlorous acid.

\begin{tabular}{lccc}
\hline NSAID $(\mu \mathrm{M})$ & $\begin{array}{c}\text { Chlorination activity } \\
\text { (\% inhibition) }\end{array}$ & $\begin{array}{c}\text { Peroxidation activity } \\
\text { (\% inhibition) }\end{array}$ & $\begin{array}{c}\mathrm{HOClC}(\mu \mathrm{M}) \\
\text { (scavenging) }\end{array}$ \\
\hline $\begin{array}{l}\text { Diclofenac } \\
3.6^{\mathrm{a}}\end{array}$ & $45 \pm 3^{*}$ & $36 \pm 10^{*}$ & $\mathrm{NS}$ \\
$36^{\mathrm{b}}$ & $86 \pm 1^{*}$ & $71 \pm 2^{*}$ & $10.8 \pm 1.5^{*}$ \\
$\begin{array}{l}\text { Indomethacin } \\
12^{\mathrm{a}}\end{array}$ & $100 \pm 1^{*}$ & $97 \pm 2^{*}$ & $\mathrm{NS}$ \\
$120^{\mathrm{b}}$ & $100 \pm 1^{*}$ & $99 \pm 1^{*}$ & $\mathrm{NS}$ \\
Naproxen & & & $\mathrm{NS}$ \\
$160^{\mathrm{a}}$ & $76 \pm 3^{*}$ & $56 \pm 8^{*}$ & $\mathrm{NS}$ \\
$1600^{\mathrm{b}}$ & $85 \pm 3^{*}$ & $62 \pm 2^{*}$ & \\
Piroxicam & $99 \pm 1^{*}$ & $77 \pm 5^{*}$ & $11.7 \pm 1.4^{*}$ \\
$13^{\mathrm{a}}$ & $100 \pm 2^{*}$ & $89 \pm 2^{*}$ & $12.4 \pm 11^{*}$ \\
$130^{\mathrm{b}}$ & & & \\
Tenoxicam & $100 \pm 1^{*}$ & $90 \pm 2^{*}$ & $11.7 \pm 11^{*}$ \\
$30^{\mathrm{a}}$ & $100 \pm 2^{*}$ & $97 \pm 1^{*}$ & $12.7 \pm 1.3^{*}$ \\
$300^{\mathrm{b}}$ & & &
\end{tabular}

Data are reported as the means \pm SD of 6 experiments. ${ }^{\text {aTherapeutic plasma }}$ concentration; bten times higher than the therapeutic plasma concentration; consumption of $\mathrm{HOCl}$ by NSAIDs after incubation for $10 \mathrm{~min}$ detected by the 5 -thio2-nitrobenzoic acid assay (see Experimental section). $\mathrm{HOCl}=$ hypochlorous acid; NSAIDs $=$ nonsteroidal anti-inflammatory drugs.

${ }^{*} \mathrm{P}<0.05$ compared to controls: $1.3 \pm 0.2 \times 10^{5}(\mathrm{mV} \cdot \mathrm{s})$ for chlorination activity or $1270 \pm 160(\mathrm{mV} \cdot \mathrm{s})$ for peroxidation activity (Student $t$-test). NS = nonsignificant. 


\section{Discussion}

It has been reported that some NSAIDs act as scavengers of ROS produced when neutrophils are stimulated with opsonized zymosan or via the soluble PMA stimulus $(19,25,26)$. However, there is no report about whether their therapeutic plasma concentrations are able to affect neutrophil oxidative function. In the present study, we advanced in this area by studying the effects of therapeutic plasma concentrations of NSAIDs on ROS production by stimulated neutrophils. Besides the cell system assays, we also assessed the properties of NSAIDs as MPO inhibitors by the luminol-dependent chemiluminescent technique. We found that, except for naproxen, the therapeutic plasma concentrations of the NSAIDs tested here are sufficient to inhibit the luminol-dependent chemiluminescence generated by activated neutrophils. Similar results were obtained using cell-free systems, in which the pres-

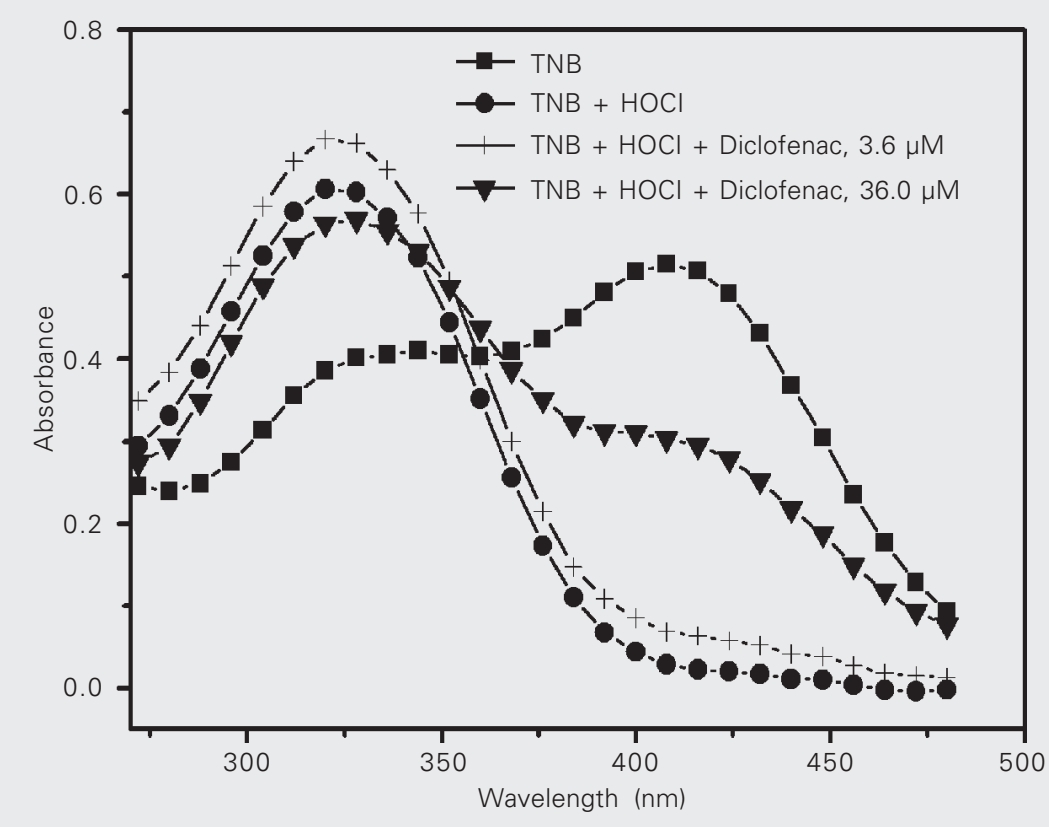

Figure 3. Scavenger of $\mathrm{HOCl}$ by diclofenac (TNB assay). The concentrations of diclofenac represent the therapeutic dose and a dose 10 times higher. The reduction of the absorbance decreases at $412 \mathrm{~nm}$ compared to control (TNB $+\mathrm{HOCl}$ trace) denotes the scavenging property of the diclofenac. The traces are representative of 6 experiments. $\mathrm{TNB}=$ 5-thio-2-nitrobenzoic acid; $\mathrm{HOCl}=$ hypochlorous acid. ence or absence of chloride in the buffer dictates the mechanism of luminol chemiluminescence. In fact, it has been demonstrated that $\mathrm{HOCl}$ oxidizes luminol when the $\mathrm{MPO} / \mathrm{H}_{2} \mathrm{O}_{2}$ system is operating in chloridecontaining buffers (Reactions 1-3). In contrast, in the absence of chloride, luminol oxidation occurs through a classical peroxidation mechanism via the intermediate compound-I and compound-II of MPO (Reactions 1 and 4-6) (31).

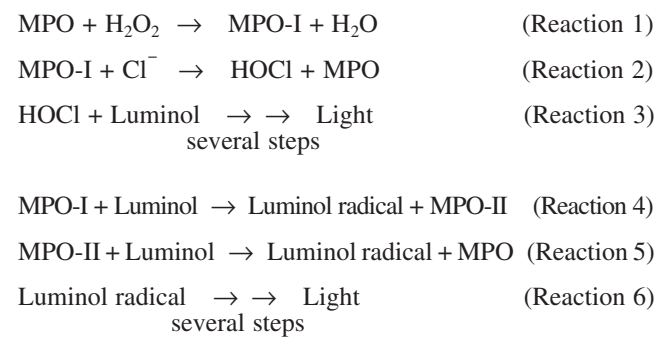

This property of MPO-catalyzed luminol oxidation is useful to assess whether a molecule is able to compete for the active site of the enzyme or whether it is only able to react with the generated $\mathrm{HOCl}$. Here we obtained a similar inhibition pattern for each NSAID studied in both assays, which indicates that these compounds at their therapeutic plasma concentration are able to compete with chloride for the catalytic site of MPO, leading to the inhibition of $\mathrm{HOCl}$ production. Besides inhibiting $\mathrm{HOCl}$ production, therapeutic plasma levels of piroxicam and tenoxicam and the 10 times higher concentration of diclofenac were also able to react with pure $\mathrm{HOCl}$. This additional chemical property of some NSAIDs could contribute to the suppression of this oxidant species at the inflammatory site.

As demonstrated by lucigenin-dependent chemiluminescence, the drugs tested here were less effective inhibitors of superoxide anion. Only indomethacin was able to inhibit its generation in a statistically significant manner. Interestingly, diclofenac was able to promote the generation of superoxide anion 
instead of inhibiting it and this effect seems to be related to the activation of NADPHoxidase, as detected by the increased oxygen uptake by the stimulated neutrophils. These results show that further experiments are needed to identify the effects of NSAIDs on the neutrophil oxidative burst. Indeed, the reports are contradictory about the effect of diclofenac and indomethacin on ROS generation. For instance, Al-Arfaj et al. (32) reported an increase in both isolated neutrophil and whole blood chemiluminescence when subjects were treated with diclofenac. Similar results were reported for indomethacin when superoxide anion generated by neutrophils was measured by the reduction of ferricytochrome C (33). However, Parij et al. (19) have reported chemiluminescence suppression by both the luminol and lucigenin techniques.

Taken together, the results obtained in the luminol and lucigenin assays lead us to conclude that the major effect of NSAIDs on oxygen-dependent antimicrobial or oxidative neutrophil functions was to impair the generation of $\mathrm{HOCl}$ by competing with chloride for the active site of MPO without inhibiting the NADPH-oxidase enzymatic complex, except for indomethacin.

It was not our aim in this investigation to determine the reasons why some NSAIDs are more potent MPO inhibitors than others and additional experiments are needed to address this question. Nevertheless, the results showed that phenol derivatives such as piroxicam and tenoxicam were more effective than non-phenol structured compounds as diclofenac and naproxen, despite the higher concentration used for the last one. This is not unexpected since phenol compounds are typical MPO substrates (34). Moreover, indomethacin, which is also an MPO substrate, was as efficient as piroxicam and tenoxicam (15).

The results obtained for the cell system were more complex. Again, naproxen was an ineffective MPO inhibitor, and piroxicam and tenoxicam were less efficient compared to the enzymatic system. Certainly, other factors are involved and an important difference between the enzymatic and cell systems is the presence of superoxide anion in the latter. In this respect, it has been postulated that superoxide anion is able to react with MPO-II, leading to the native form of MPO (35). Since MPO-II is an inactive chlorinating species, the recycling of this intermediate by superoxide anion may augment the production of $\mathrm{HOCl}$ in the cell system, which may explain the reduced $\mathrm{HOCl}$ suppression effect observed compared to the enzymatic system. It is also important to consider the inhibition of cyclooxygenases by NSAIDs, which could promote the accumulation of arachidonic acid. In fact, it has been proposed that arachidonic acid is able to directly activate NADPH oxidase, inducing intact neutrophils to generate superoxide anion through a protein kinase-independent pathway (36). Moreover, the ROS could be generated by the 5-lipoxygenase pathway through the $\mathrm{B}_{4}$ leukotriene (37).

Endogenous oxidizing species such as $\mathrm{HOCl}$ play an important role in the pathophysiology of inflammatory disease, not only as terminal effectors, but also as secondary messengers in signal transduction. For instance, $\mathrm{HOCl}$ induced tumor necrosis factor-alpha production in peripheral blood mononuclear cells in a tyrosine kinase-dependent manner (38). Thus, the finding that therapeutic plasma levels of NSAIDs are able to suppress the generation of $\mathrm{HOCl}$ implies that the mechanism of the anti-inflammatory action of these drugs may be also linked to this reaction.

The MPO-catalyzed oxidation of NSAIDs may also have a direct influence on their toxic side effect. Recent research has focused on the pro-oxidant property of some NSAIDs. For example, the horseradish peroxidasemediated oxidation of biomolecules like ascorbic acid, NADH and glutathione is promoted when these NSAIDs are added to the reac- 
tion medium (39). This pro-oxidant activity is based on the accelerated oxidation of these biomolecules by NSAID radicals and on the generation of reactive metabolites by the peroxidase-catalyzed reaction. In this respect, the iminoquinone formed by the reaction between diclofenac and $\mathrm{HOCl}$ or activated neutrophils has been proposed as another possible cause of idiosyncratic reactions associated with the use of diclofenac (40). Accordingly, we observed that diclofenac reacted with $\mathrm{HOCl}$ and also to stimulate the production of superoxide anion.

We have demonstrated that therapeutic plasma levels of classical NSAIDs are able to suppress the oxygen-dependent antimicrobial or oxidative functions of neutrophils by inhibiting the MPO-chlorinating activity and also by scavenging $\mathrm{HOCl}$. The efficiency of inhibition is variable, but at least $50 \%$ inhibition was obtained with the drugs tested here. From a different point of view, our results support the idea that oxidized intermediates of NSAIDs may be formed when the drugs are administered therapeutically and these metabolites may be partially responsible for the helpful and adverse effects of NSAIDs.

\section{References}

1. Dahlgren C \& Karlsson A (1999). Respiratory burst in human neutrophils. Journal of Immunological Methods, 232: 3-14.

2. Babior BM (2000). Phagocytes and oxidative stress. American Journal of Medicine, 109: 33-44.

3. Hampton MB, Kettle AJ \& Winterbourn CC (1998). Inside the neutrophil phagosome: oxidants, myeloperoxidase, and bacterial killing. Blood, 92: 3007-3017

4. Podrez EA, Abu-Soud HM \& Hazen SL (2000). Myeloperoxidasegenerated oxidants and atherosclerosis. Free Radical Biology and Medicine, 28: 1717-1725.

5. Lapenna D \& Cuccurullo F (1996). Hypochlorous acid and its pharmacological antagonism: an update picture. General Pharmacology, 27: 1147-1154.

6. Heinecke JW, Li W, Mueller DM, Bohrer A \& Turk J (1994). Cholesterol chlorohydrin synthesis by the myeloperoxidase-hydrogen peroxide-chloride system: potential markers for lipoproteins oxidatively damaged by phagocytes. Biochemistry, 33: 1012710136

7. Spickett CM, Jerlich A, Panasenko OM, Arnhold J, Pitt AR, Stelmaszynska T \& Schaur RJ (2000). The reactions of hypochlorous acid, the reactive oxygen species produced by myeloperoxidase, with lipids. Acta Biochimica Polonica, 47: 889-899.

8. Domigan NM, Charlton TS, Duncan MW, Winterbourn CC \& Kettle AJ (1995). Chlorination of tyrosyl residues in peptides by myeloperoxidase and human neutrophils. Journal of Biological Chemistry, 270: 16542-16548.

9. Carr AC, Decker EA, Park Y \& Frei B (2001). Comparison of lowdensity lipoprotein modification by myeloperoxidase-derived hypochlorous and hypobromous acids. Free Radical Biology and Medicine, 31: 62-72

10. Chapman AL, Winterbourn CC, Brennan SO, Jordan TW \& Kettle AJ (2003). Characterization of non-covalent oligomers of proteins treated with hypochlorous acid. Biochemical Journal, 375: 33-40.

11. Henrotin YE, Bruckner P \& Pujol JP (2003). The role of reactive oxygen species in homeostasis and degradation of cartilage. Osteoarthritis and Cartilage, 10: 747-755.

12. Turpaev KT (2002). Reactive oxygen species and regulation of gene expression. Biochemistry, 3: 292-299.
13. Kast RE (2000). Non-steroidal anti-inflammatory drugs might also be pro-inflammatory by increasing tumor necrosis factor. Biomedical Pharmacotherapy, 54: 168-169.

14. Kast RE (2000). Tumor necrosis factor has positive and negative self regulatory feed back cycles centered around cAMP. International Journal of Immunopharmacology, 22: 1001-1006.

15. Ju C \& Uetrecht JP (1998). Oxidation of a metabolite of indomethacin (desmethyldeschlorobenzoylindomethacin) to reactive intermediates by activated neutrophils, hypochlorous acid, and the myeloperoxidase system. Drug Metabolism and Disposition, 26: 676-680.

16. Jacobs JWG \& Bijlsma JWJ (1997). NSAIDs: a critical appraisal Netherlands Journal of Medicine, 51: 198-204.

17. Babior MB \& Cohen HJ (1981). Measurement of neutrophil function: phagocytosis, degranulation, the respiratory burst and bactericidal killing. In: Cline MJ (Editor), Methods in Hematology: Leucocyte Function. Churchill Livingstone, New York.

18. Dorfman LE \& Wacker WEC (1963). Serum lactic dehydrogenase activity: an analytical assessment of current assays. Clinical Chemistry, 9: 391-399

19. Parij N, Nagy AM, Fondu P \& Neve J (1998). Effects of non-steroidal anti-inflammatory drugs on the luminol and lucigenin amplified chemiluminescence of human neutrophils. European Journal of Pharmacology, 352: 299-305.

20. Harrison JE \& Schultz J (1976). Studies on the chlorinating activity of myeloperoxidase. Journal of Biological Chemistry, 251: 13711374.

21. Ching $T$, Dejong J \& Bast A (1994). A method for screening hypochlorous acid scavengers by inhibition of the oxidation of 5thio-2-nitrobenzoic acid: application to anti-asthmatic drugs. Analytical Biochemistry, 218: 377-381.

22. Insel PA (1991). Substâncias analgésicas, antipiréticas e antiinflamatórias. Drogas empregadas no tratamento da artrite reumatóide e da gota. In: Gilman AG, Rall TW, Nies AS \& Taylor P (Editors), Goodman \& Gilman. As Bases Farmacológicas da Terapêutica. Guanabara \& Koogan, Rio de Janeiro, RJ, Brazil.

23. Korolkovas A (1999). Dicionário Terapêutico Guanabara 1999/2000. Guanabara-Koogan, Rio de Janeiro, RJ, Brazil. 
24. Gennaro AR (2000). Non steroidal antiinflammatory drugs. In: Limmer D (Editor), Remington: The Science and Practice of Pharmacy. Lippincott Williams \& Wilkins, Philadelphia, PA, USA.

25. Shacter E, Lopez RL \& Patis S (1991). Inhibition of the myeloperoxidase- $\mathrm{H}_{2} \mathrm{O}_{2}-\mathrm{Cl}$ system of neutrophils by indomethacin and other non-steroidal anti-inflammatory drugs. Biochemical Pharmacology, 41: 975-984.

26. Kataoka M, Tonooka K, Ando T, Imai K \& Aimoto T (1997). Hydroxyl radical scavenging activity of nonsteroidal anti-inflammatory drugs. Free Radical Research, 27: 419-427.

27. Faulkner K \& Fridolvich I (1993). Luminol and lucigenin as detectors for superoxide. Free Radical Biology and Medicine, 15: 447451.

28. Vasquez-Vivar J, Hogg N, Pritchard Jr KA, Martasek P \& Kalyanaraman B (1997). Superoxide anion formation from lucigenin: an electron spin resonance spin-trapping study. FEBS Letters, 403: 127-130.

29. Li Y, Zhu H, Kuppusamy P, Roubaud V, Zweier JL \& Trush MA (1998). Validation of lucigenin (bis-N-methylacridinium) as a chemilumigenic probe for detecting superoxide anion radical production by enzymatic and cellular systems. Journal of Biological Chemistry, 273: 2015-2023.

30. Dodeigne C, Thumus L \& Lejeune R (2000). Chemiluminescence as diagnostic tool. A review. Talanta, 51: 415-439.

31. Allen RC, Dale DC \& Taylor Jr FB (2000). Blood phagocyte luminescence: gauging systemic immune activation. Methods in Enzymology, 305: 591-609.

32. Al-Arfaj AS, Alballa SR, Mustafa AA, Al-Tuwaijri AS, Al-Dalaan AN \& Al-Humayyd MS (2004). Effect of diclofenac alone or in combination with alpha-tocopherol on the oxidative activity of polymorpho- nuclear leukocytes in healthy and osteoarthritic individuals. Saudi Medical Journal, 25: 198-203.

33. Bekesi G, Kakucs R, Sandor J et al. (2001). Plasma concentration of myeloperoxidase enzyme in pre- and post-climacterial people: related superoxide anion generation. Experimental Gerontology, 37: 137-148.

34. Kato Y, Nagao A, Terao J \& Osawa T (2003). Inhibition of myeloperoxidase-catalyzed tyrosylation by phenolic antioxidants in vitro. Bioscience, Biotechnology, and Biochemistry, 67: 1136-1139.

35. Ghibaudi E \& Laurenti E (2003). Unraveling the catalytic mechanism of lactoperoxidase and myeloperoxidase. European Journal of Biochemistry, 270: 4403-4412.

36. Hartfield PJ \& Robinson JM (1998). Arachidonic acid activates NADPH oxidase by a direct, calmodulin-regulated mechanism. Prostaglandins and Other Lipid Mediators, 56: 1-6.

37. Woo CH, You HJ, Cho SH, Eom YW, Chun JS, Yoo YJ \& Kim JH (2002). Leukotriene $B_{4}$ stimulates Rac-ERK cascade to generate reactive oxygen species that mediates chemotaxis. Journal of Biological Chemistry, 277: 8572-8578.

38. Schieven GL, de Fex H \& Stephenson L (2002). Hypochlorous acid activates tyrosine phosphorylation signal pathways leading to calcium signaling and TNFalpha production. Antioxidants and Redox Signaling, 4: 501-507.

39. Galati G, Tafazoli S, Sabzevari O, Chan TS \& O'Brien PJ (2002). Idiosyncratic NSAID drug induced oxidative stress. Chemico-Biological Interactions, 142: 25-41.

40. Miyamoto G, Zahid N \& Uetrecht JP (1997). Oxidation of diclofenac to reactive intermediates by neutrophils, myeloperoxidase, and hypochlorous acid. Chemical Research in Toxicology, 10: 414419. 